\title{
Segurança Alimentar e Nutricional e a construção de sua política: uma visão
} histórica

\author{
Marta Battaglia Custódio ${ }^{1}$, Nelson Roberto Furquim², Greice Maria Mansini dos Santos ${ }^{3}$, \\ Denise Cavallini Cyrillo ${ }^{4}$
}

Estudos sobre a situação nutricional ressaltam a redução da prevalência de desnutrição no Brasil. Embora ainda existam casos de comunidades sob risco de déficit nutricional, também se verifica uma elevação de níveis de sobrepeso e obesidade no país. Persistem condições negativas que impactam o estado nutricional da população, como a elevada concentração de renda, altos níveis de analfabetismo funcional e discriminação social e racial. É importante conhecer a evolução histórica das políticas públicas voltadas para a questão alimentar e nutricional para aprimorar o debate em torno do combate à fome e à desnutrição. O Programa Fome Zero, lançado em 2003, foi concebido em torno de quatro eixos, a saber: o acesso aos alimentos; o fortalecimento da agricultura familiar; a geração de renda; e a articulação, mobilização e controle social. Além dele, a Lei Orgânica, instituída em 2006, contribuiu para a construção do arcabouço legal da Política Nacional de Segurança Alimentar e Nutricional.

Palavras-chave: segurança alimentar e nutricional, política pública, combate à fome.

\section{Building a Brazilian Food and Nutritional Security Policy. A historical approach}

Studies on the nutritional status of the Brazilian population detect a reduction of malnutrition. Although there are still cases of communities at risk of nutritional deficit, an increase of overweight and obesity levels is also evident. Negative factors, such as a run-away elevation of income concentration, high levels of illiteracy and social and racial discrimination contribute to malnutrition. It is important to know the historical evolution of all feeding and nutrition policies in order to improve the debate on how to combat hunger and malnutrition. The Fome Zero Program, launched in 2003, was conceived around four axes: The access to food; strengthening of family agriculture; income generation; and a concerted social mobilization and control. Additionally, the Organic Law, instituted in 2006, contributed for the construction of the National Policy of Food and Nutrition Security.

Key-words: food and nutritional security, public policy, fight against hunger.

\footnotetext{
${ }^{1}$ Dra. em Nutrição Humana Aplicada pelo Programa de Pós-graduação em Nutrição Humana Aplicada (PRONUT), Universidade de São Paulo, USP.

${ }^{2}$ Doutorando em Nutrição Humana Aplicada pelo PRONUT, USP.

${ }^{3}$ Mestranda em Nutrição Humana Aplicada, pelo PRONUT, USP.

${ }^{4}$ Profa. Associada da Faculdade de Economia, Administração e Contabilidade (FEA/USP) e Profa. Credenciada do PRONUT, USP.

Correspondência: Av. Prof. Luciano Gualberto, 908. Cidade Universitária. Prédio FEA 1, Sala 101C, CEP 05508-900, São Paulo, SP. E-mail: dccyrill@usp.br.
} 


\section{INTRODUÇÃO}

A Constituição Brasileira de 1988 instituiu a saúde como resultante de diversas condições, tais como alimentação, educação, trabalho, renda, acesso aos serviços de saúde, dentre outras, sendo um direito garantido por meio da implantação de políticas econômicas e sociais, que devem promover a integração de diversos setores de governo ${ }^{[1]}$.

A Lei no 11.346, de 15 de setembro de 2006, cria o Sistema Nacional de Segurança Alimentar e Nutricional (SISAN), com vistas a assegurar o Direito Humano à Alimentação Adequada (DHAA) e dá outras providências envolvendo a integração entre diferentes setores governamentais [2].

A intersetorialidade, característica comum entre estes dois marcos legais, exige estratégias de caráter institucional para que possa ser efetiva. Ressaltase assim a importância de políticas públicas integratórias como diferenciais para o desenvolvimento do país, verificadas principalmente a partir da década de 1980, com a implantação de formatos de gestão híbridos, envolvendo diferentes setores da sociedade e do governo [3].

Como ressaltam Burlandy \& Magalhães [4], a distribuição e o acesso aos alimentos são pressupostos para a garantia do Direito Humano à Alimentação, no que diz respeito à promoção da equidade nutricional e da alimentação saudável e ao combate da desnutrição. Essa visão reforça o caráter da desnutrição enquanto uma doença social, como apontado por Josué de Castro (1946) [5].

Historicamente, o conceito de Segurança Alimentar e Nutricional (SAN) vem sendo fortalecido, ampliado e refletido na intersetorialidade das políticas públicas federais ${ }^{[3]}$.

O presente artigo tem por objetivo apresentar uma visão histórica da construção do conceito de Segurança Alimentar e Nutricional, como base de uma política nacional estruturada, interdisciplinar e intersetorial potencialmente capaz de transformar a realidade econômica e social.

\section{EVOLUÇÃO DA DISCUSSÃO SOBRE FOME E SEGURANÇA ALIMENTAR NO BRASIL E NO MUNDO}

O DHAA, de acordo com as Nações Unidas, tem como bases a Declaração Universal dos Direitos Humanos e o Pacto Internacional Relativo aos Direitos Econômicos, Sociais e Culturais (PIDESC). Esse último foi aberto a adesões em 1966, porém passou a vigorar somente em 3 de janeiro de 1976, quando atingiu um número significativo de signatários [ [ ${ }^{\circ}$.

No Brasil, os direitos explicitados no PIDESC entraram no ordenamento jurídico quinze anos depois, pela aprovação do Decreto Legislativo no 226, de 12 de dezembro de 1991, do Congresso Nacional [7]. Com a realização, em 1994, da I Conferência Nacional de Segurança Alimentar (I CNSA) ${ }^{[8]}$, com o objetivo de discutir as diretrizes para a elaboração de uma Política Nacional de Segurança Alimentar e Nutricional (PNSAN), ampliou-se a discussão e os debates sobre a promoção dos Direitos Humano, Econômicos, Sociais e Culturais (DHESC), entre eles o DHAA.

O tema SAN é bastante amplo, envolvendo aspectos tanto de oferta (produção, desenvolvimento sustentável, abastecimento e comercialização), quanto de demanda (aproveitamento e aquisição) de alimentos. $\mathrm{O}$ tema pode ser analisado sob o ponto de vista micro ou macroeconômico.

O conceito de Segurança Alimentar teve sua origem na Europa do início do século XX e refletia a capacidade de cada país de produzir sua própria alimentação, evitando assim vulnerabilidades, e adquiriu uma perspectiva internacional com a criação da Organização das Nações Unidas (ONU) e da Organização das Nações Unidas para a Agricultura e a Alimentação (FAO), bem como de outros organismos financeiros internacionais [?].

No período que se seguiu após a II Guerra Mundial, houve um compromisso internacional em torno de objetivos e práticas a serem seguidos pelas nações, com o intuito de evitar que novo conflito mundial ocorresse nos moldes e nas dimensões das duas grandes guerras do século XX. Este compromisso foi formalizado em torno da criação da ONU, em cujo discurso brotava a crença "aos direitos fundamentais do Homem, à dignidade e ao valor da pessoa humana, à igualdade de direitos dos homens e das mulheres e das nações grandes e pequenas" e no estabelecimento de condições para garantir a justiça e o respeito aos tratados internacionais e outros acordos ${ }^{[10]}$.

Além da questão da fome, problema premente e de curto prazo, aspectos de longo prazo começaram a 
serem percebidos. A despeito dos fortes ganhos de produtividade, obtidos pelas novas técnicas, ao final da década de 1980, os danos de tal processo, para o meio ambiente, já se mostravam patentes, particularmente para os países em desenvolvimento, com a destruição do equilíbrio dos agroecossistemas a ponto de colocar em risco a perenidade dos recursos naturais. A questão da qualidade dos alimentos não era, naquele momento, o principal foco das atenções do ocidente, conforme Flandrin \& Montanari [11]:

\begin{abstract}
Após 1948, quando uma aparência de ordem foi restabelecida nos mercados e as pessoas voltaram a ter a impressão de que estavam na boa extremidade da cornucópia da abundância, as preocupações com a higiene dietética foram relegadas para o segundo plano. A era do baby boom - entre 1946 e 1963 - foi marcada pela família: os americanos fundaram milhões de lares e sua principal preocupação era a adaptação à nova realidade. No plano alimentar, as questões de saúde ou gastronomia cederam lugar à "comodidade"; isso marcou o início do que os fabricantes de alimentos industriais designaram por "prontoa-servir" (1998, p. 835) [11].
\end{abstract}

Firmava-se assim a visão de que o aumento da produção de alimentos e a auto-suficiência não bastavam para eliminar a fome de um país e aflorava a ideia de promoção do progresso social e de melhores padrões de vida [?].

A partir da crise de escassez de 1972-74 e com a repercussão da Conferência Mundial de Alimentação de 1974 o conceito de Segurança Alimentar passa a ser difundido internacionalmente, porém afastando-se do foco original das Nações Unidas (fundado nos Direitos Humanos), e no decorrer dos anos 1980, volta-se para a questão do acesso (demanda e distribuição), colocando em segundo plano a da oferta de alimentos [?].

O componente "nutricional" no conceito de Segurança Alimentar ganhou força no final dos anos 1980. Em 1992 a FAO reiterou a importância da qualidade nutricional, sanitária, biológica e cultural dos alimentos para a SAN [12].
Ao longo do processo preparatório para a Cúpula Mundial de Alimentação de 1996, foram emanadas contribuições do Comitê Nacional e da I CNSA realizada em 1994, em Brasilia (DF), que constituíram a base do relatório sobre a situação da Segurança Alimentar e da Fome no Brasil [13]. Tal documento foi entregue em 1996, pelo governo brasileiro, à Cúpula Mundial de Alimentação, em Roma, na Itália, por uma comissão tripartite (formada pela sociedade civil, governo e iniciativa privada). Nele, SAN foi conceituada como segue:

\begin{abstract}
Segurança Alimentar e Nutricional consiste em garantir a todos condições de acesso a alimentos básicos, seguros e de qualidade, em quantidade suficiente, de modo permanente e sem comprometer o acesso a outras necessidades essenciais, com base em práticas alimentares saudáveis, contribuindo assim para uma existência digna em um contexto de desenvolvimento integral da pessoa humana (BRASIL, 1996, p. 4) [13].
\end{abstract}

Em 1996, ocorreu a Cúpula Mundial de Alimentação, momento em que Chefes de Estado e de Governo reafirmaram o direito dos homens de terem acesso a alimentos seguros e nutritivos. O compromisso número um desta cúpula foi garantir um ambiente político, social e econômico propício, destinado a criar as melhores condições para erradicar a pobreza e para uma paz duradoura, baseada numa participação plena e igualitária de homens e mulheres, que favoreça ao máximo a realização de uma segurança alimentar sustentável para todos [14].

Em 2001, ocorreu o Fórum Mundial sobre Soberania Alimentar, na cidade de Havana, em Cuba, com o objetivo de analisar a perda de soberania sobre os recursos alimentares dos países do terceiro mundo [15].

É importante perceber que a soberania alimentar constitui bandeira de movimentos sociais ligados à reforma agrária, ao se rebelarem contra a lógica do capital que se impõe à produção agropecuária dos países em desenvolvimento, determinando o que e como produzir, não para quem tem fome, mas para quem tem dinheiro. O conceito de SAN, por sua vez, tem um apelo técnico, sob o qual é possível estruturar 
uma política nacional, como está ocorrendo no Brasil: a construção de uma política de Estado e não apenas de um governo, abrigando em seus meandros a soberania alimentar, seja inserida no SISAN [16], seja no Programa Territórios da Cidadania, lançado pelo Governo Federal, sob o Ministério do Desenvolvimento Agrário (MDA) em 2008 [17].

\section{HISTÓRICO DAS POLÍTICAS PÚBLICAS DE ALIMENTAÇÃO E NUTRIÇÃO NO BRASIL}

\section{Até meados dos anos 1980}

O Brasil tem longa experiência na implementação de programas sociais voltados para a questão alimentar e nutricional, como por exemplo, o Programa Nacional de Alimentação Escolar (PNAE), formalizado em 1983, porém, cuja origem data do ano de 1954; o Programa de Alimentação do Trabalhador (PAT), criado em 1976 e o Programa Nacional de Alimentação e Nutrição (PRONAN), de 1973, entre outros. Todavia a descontinuidade e desarticulação entre os diversos programas descaracterizam esta experiência como uma política pública coerente e sistemática.

Uma das primeiras iniciativas foi o Serviço de Abastecimento da Previdência Social (SAPS), de 1955, que entre as suas ações distribuía alimentos básicos aos inscritos na Previdência Social. Como é apontado por Escoda [18], esse órgão foi transformado na Companhia Brasileira de Alimentos (COBAL), em 1962. O programa de merenda escolar, o mais antigo programa de alimentação existente no país, começou a ser construído na década de 1940, quando o Instituto de Nutrição defendia a distribuição de alimentação escolar, em nível federal. $\mathrm{Na}$ década seguinte, surgiu o Conjuntura Alimentar e o Problema da Nutrição no Brasil, dentro do qual se estruturou a merenda escolar com abrangência nacional, como programa público, além de outras ações na área de alimentação e nutrição. Desse conjunto de ações, apenas a merenda escolar sobreviveu, sendo financiada pelo Fundo Internacional de Socorro à Infância (hoje denominado Fundo das Nações Unidas para a Infância, UNICEF). A maior parte desse financiamento se deu em espécie, na forma de leite em pó produzido em excesso pela economia norte-americana. Foi em março de 1955, que o programa adquiriu novo status, por meio de Decreto que deu ao Ministério da Educação a incumbência de gerir a Campanha de Merenda Escolar, ainda com apoios internacionais [19].

Em meio a uma crise mundial de subnutrição, foi criado o Instituto Nacional de Alimentação e Nutrição (INAN) no Brasil (1972), com a incumbência de elaborar uma política nacional capaz de combater os problemas nutricionais do país. Um conjunto de dez programas foi elaborado buscando atender as necessidades dos diversos segmentos vulneráveis da população, crianças e gestantes, área rurais, trabalhadores, etc. Foi o I PRONAN, com metas para o período de 1976 a 1979, que envolvia quatro grandes eixos, com um caráter multisetorial e integrado: Suplementação alimentar a gestantes, nutrizes e crianças, em caráter transitório; apoio ao pequeno produtor de áreas de baixa renda; programas de fortificação e incentivo à alimentação do trabalhador. As ações voltadas para a produção - fossem às dirigidas aos pequenos produtores ou aos trabalhadores urbanos - possibilitariam o aumento da oferta, que seria utilizada na suplementação alimentar [20]. Autores como Escoda [18] já se perguntavam se as ações implementadas pelo PRONAN, que tinham a pretensão de dar uma resposta à problemática da nutrição, proporcional à dimensão do problema social nela envolvido, seriam capazes de efetivamente transformar as estruturas e romper com o ciclo vicioso da pobreza e da desnutrição.

O II PRONAN (1976) foi redigido, mas não chegou a ser implantado, muito embora alguns programas tenham se mantido "vivos" ao longo da história da política nacional de alimentação e nutrição, como a merenda escolar, hoje o PNAE, e o PAT. Com o advento do Fome Zero, estes foram incorporados sob a perspectiva de uma política nacional intersetorial, descentralizada e integrada.

Em meados da década de 1980, o Ministério da Agricultura propôs uma "Política Nacional de Segurança Alimentar", com ênfase na auto-suficiência na produção de alimentos, criando o Conselho Nacional de Segurança Alimentar (CONSEA). Em 1986, houve a instalação da I Conferência Nacional de Alimentação e Nutrição, convocada pelo INAN, porém com poucos resultados práticos ${ }^{[12]}$.

O INAN foi extinto em 1997 e em 1999 foi aprovada a Política Nacional de Alimentação e Nutrição (PNAN), integrando a Política Nacional de Saúde (PNS), do Ministério da Saúde [21]. 


\section{Transição para o Século XXI}

A década seguinte foi essencial ao projeto Fome Zero. Lançado como prioridade do governo federal brasileiro, no início de 2003, na realidade ele teve início uma década antes, pois foi elaborado a partir de uma proposta de Política de Segurança Alimentar e Nutricional realizada pelo Instituto da Cidadania ao longo dos anos 1990 [12].

Esta proposta foi acolhida pelo Governo Federal por meio de três decisões importantes, em 1993, a saber: (1) a elaboração do "Mapa da fome" pelo Instituto de Pesquisa Econômica Aplicada (IPEA), que mensurou o número de pessoas sem renda para adquirir alimentos no Brasil; (2) a apresentação de um Plano de Combate à Fome e à Miséria; e (3) a criação do CONSEA, integrado por oito ministros e vinte e um conselheiros da sociedade civil [12].

A conjuntura política no início dos anos 1990 acabou sendo utilizada pelos movimentos sociais para avançar na proposição de políticas públicas. Nesse cenário ocorreu, em 1994, a I CNSA, onde foram discutidas questões relativas à construção de uma política nacional de SAN e onde foram traçadas prioridades, como a redução do custo dos alimentos no orçamento familiar, a garantia de saúde e alimentação para segmentos específicos da população e a garantia da qualidade biológica, sanitária, nutricional e tecnológica dos alimentos. A partir desta Conferência foi construído o conceito brasileiro de Segurança Alimentar, que foi logo em seguida adotado pela FAO, conforme já mencionado, durante a Cúpula Mundial da Alimentação, em Roma, no ano de 1996.

Em 1994 ocorreram novas eleições estaduais e federais. O novo governo extinguiu o CONSEA e criou o Conselho do Programa Comunidade Solidária, que não priorizou o tema da SAN como fazia o Conselho.

Segundo Pessanha [22] o Programa Comunidade Solidária deslocou o centro das discussões da fome e da segurança alimentar para a questão da pobreza, sendo que as possibilidades de ação integrada dos diferentes atores sociais (governo e sociedade civil) seriam instrumento para a sua superação e que o gerenciamento dos programas sociais deveria ser descentralizado em parceria com a sociedade civil.
Entretanto, a política macroeconômica no período teve como objetivo prioritário a garantia da estabilidade monetária e o Programa Comunidade Solidária foi relegado a segundo plano, não inserido entre as prioridades governamentais [22].

As principais críticas ao Programa Comunidade Solidária foram a focalização e a descentralização da assistência social, pois apontavam para o uso clientelista desta política e para a desarticulação das alianças e parcerias consolidadas anteriormente no âmbito do CONSEA [22].

Apesar destes fatos, alguns avanços importantes para a implementação de uma PNSAN foram iniciados, dentre eles a implementação do Programa Nacional de Apoio à Agricultura Familiar (PRONAF), em 1996, e a aprovação da PNAN, por meio da Portaria no 710 do Ministério da Saúde, em 1999 [23].

O PRONAF foi implementado com o intuito de direcionar recursos para os agricultores familiares, principalmente os de "maior dificuldade de integração econômica", em três modalidades: (1) crédito; (2) infraestrutura/serviços municipais e (3) capacitação [24].

A PNAN constituiu-se como um compromisso do Ministério da Saúde com os males relacionados à escassez alimentar e à pobreza, sobretudo a desnutrição infantil e materna, assim como o complexo quadro dos excessos já configurado no Brasil pelas altas taxas de prevalência de sobrepeso e obesidade, na população adulta ${ }^{[25]}$. A PNAN previa sua atuação a partir do engajamento de pessoas, instituições governamentais e não-governamentais que atuassem no campo da alimentação e nutrição, servindo como marco conceitual de ação governamental. A PNAN apresentou sete diretrizes programáticas:

1. Estímulo a ações intersetoriais com vistas ao acesso universal aos alimentos;

2. Garantia da segurança e qualidade dos alimentos;

3. Monitoramento da situação alimentar e nutricional;

4. Promoção de práticas alimentares e estilos de vida saudáveis;

5. Prevenção e controle dos distúrbios e doenças nutricionais;

6. Promoção do desenvolvimento de linhas de investigação; 
7. Desenvolvimento e capacitação de recursos humanos em saúde e nutrição.

Se, por um lado, pelas diretrizes apresentadas, observa-se que a PNAN contemplava uma abordagem intersetorial da política e que a PNSAN, ora em construção, também compartilha desta mesma visão, de que a natureza transversal é intrínseca à questão alimentar e nutricional, por outro, é possível fazer uma clara distinção entre elas, uma vez que a segunda estabelece como eixo central de sua atuação a garantia ao DHAA e considera a participação social como elemento básico na formulação da política, enquanto que a PNAN apresentava um enfoque mais qualitativo e menos participativo, prevendo que,

Em observância aos princípios do Sistema Único de Saúde (SUS), os gestores, de forma articulada e dando cumprimento às suas atribuições comuns e específicas, atuarão no sentido de viabilizar o alcance do propósito desta Política Nacional de Alimentação e Nutrição, que é a garantia da qualidade dos alimentos colocados para consumo no País, a promoção de práticas alimentares saudáveis e a prevenção e o controle dos distúrbios nutricionais (BRASIL, 2003, p. 29) [25].

\section{O Fome Zero e o Sistema Nacional de Segurança Alimentar e Nutricional (SISAN)}

O projeto Fome Zero, elaborado pelo Instituto da Cidadania ao longo dos anos 1990 para o combate à fome, partia de algumas premissas: "a fome não tem diminuído no mundo"; "a fome não é causada pelo aumento da população nem pela falta de alimentos no mundo"; "existe um mercado da fome no mundo"; "no Brasil, a pobreza e a fome não estão concentradas nas áreas rurais do Nordeste"; e "as forças de mercado não resolvem o problema da fome” [15].

O lançamento do Projeto Fome Zero como prioridade do governo eleito em 2002, quando da posse deste, e a reinstalação imediata do CONSEA propiciaram a construção de uma política abrangente que procurava englobar os diversos aspectos relacionados à $\mathrm{SAN}$.
Outro aspecto importante para a construção de uma Política Nacional de SAN foi o estímulo e a realização das II e III Conferências Nacionais de Segurança Alimentar e Nutricional (CNSAN), sendo a II CNSAN em Olinda/PE, em 2004, e a III CNSAN, em Fortaleza/CE, em 2008, esta com a presença de quase 2.000 delegados e convidados de todos os Estados brasileiros e do Distrito Federal, apoiadas por conferências em nível municipal e estadual.

Em nível internacional, em novembro de 2004, foram aprovadas as Diretrizes Voluntárias pelo Conselho da FAO, um conjunto de recomendações de adesão voluntária, ao qual o Brasil é signatário. Estas Diretrizes representaram a primeira iniciativa de governos em interpretar um direito no sentido de recomendar ações para apoiar a sua realização. Seus objetivos são proporcionar uma orientação aos Estados membros das Nações Unidas para garantir que o direito à alimentação adequada, no contexto da segurança alimentar nacional, seja alcançado em sintonia com os compromissos e objetivos do Plano de Ação da Cúpula Mundial da Alimentação [26].

O Brasil, contribuindo para a construção de um ambiente propício para que as pessoas possam se alimentar com dignidade sancionou, em setembro de

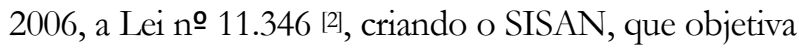
assegurar o DHAA. O principal objetivo do SISAN é formular e implementar políticas e planos de SAN, estimular a integração dos esforços entre governo e sociedade civil, bem como promover o acompanhamento, o monitoramento e a avaliação da SAN do país. A lei estabelece os componentes (membros do governo e da sociedade civil, o CONSEA e a Conferência Nacional de SAN) que integram o SISAN, por meio do qual o poder público, com a participação da sociedade civil organizada, deverá atuar com vistas a assegurar o DHAA. Ela prevê que o SISAN funcione, de forma integrada, por meio de um conjunto de órgãos públicos e de instituições privadas, com ou sem fins lucrativos, relacionadas à SAN, obedecendo a um conjunto de princípios e diretrizes.

Esta lei considera que a alimentação adequada é direito fundamental do ser humano, inerente à dignidade da pessoa humana e indispensável à realização dos direitos consagrados na Constituição Federal, devendo o poder público adotar as políticas e ações que se façam necessárias para promover e garantir a SAN da população. Ainda de acordo com a 
lei, a adoção dessas políticas e ações deverá levar em conta as dimensões ambientais, culturais, econômicas, regionais e sociais [2].

Tanto as Diretrizes Voluntárias da FAO, como o SISAN e os programas de SAN implementados no Brasil, ainda que de forma dispersa, representam instrumentos para o combate à fome e à pobreza em consonância à primeira das Metas de Desenvolvimento do Milênio [10]. As oito metas de desenvolvimento estabelecidas pela ONU para o milênio são: (1) erradicar a extrema pobreza e a fome; (2) universalizar o ensino fundamental; (3) promover a igualdade de gênero e empoderamento das mulheres; (4) reduzir a mortalidade infantil; (5) melhorar a saúde das gestantes e mães; (6) combater HIV/AIDS (Síndrome da Imunodeficiência Adquirida), malária e outras doenças; (7) assegurar o desenvolvimento sustentável; e (8) desenvolver parceria global de desenvolvimento.

Segundo Jacques Diouf, diretor geral da FAO,

O esforço para assegurar que cada criança, mulher e homem tenham direito à alimentação adequada de forma regular não constitui apenas um imperativo moral e um investimento com enorme retorno econômico; também significa a realização de um direito humano fundamental (2005 apud FAO, 2005) [27].

De acordo com a Constituição Federal [1] vigente no país, são princípios fundamentais no Brasil a soberania, a cidadania, a dignidade da pessoa humana, os valores sociais do trabalho e da livre iniciativa e o pluralismo político.

O Brasil aderiu aos tratados internacionais relativos aos Direitos Humanos (dentre eles o de estar livre da fome e de ter acesso à alimentação) como a carta da ONU, o PIDESC e as Diretrizes Voluntárias, e estas adesões foram ratificadas pelo Congresso Nacional, por isto elas estão em vigor, ainda que não com a força de Emenda Constitucional, uma vez que não passaram por votação especial, mas por processo simplificado (por maioria simples, em um turno em cada casa do Congresso Nacional) ${ }^{[1]}$.

\section{Cenário atual das políticas de alimentação e} nutrição brasileiras

O Fome Zero ${ }^{[28]}$ foi concebido em torno de quatro eixos, denominados articuladores:

1. Acesso aos alimentos (programas e ações de transferência de renda, alimentação e nutrição e acesso à informação e educação);

2. Fortalecimento da agricultura familiar (ações específicas que promovam a geração de renda no campo e o aumento da produção de alimentos para o consumo);

3. Geração de renda (incentivo à economia solidária e desenvolvimento de ações de qualificação da população de baixa renda) e;

\section{Articulação, mobilização e controle social.}

Com relação às ações do primeiro eixo, que visam ampliar e garantir o acesso aos alimentos, o Fome Zero se compõe das seguintes ações e programas: o Bolsa Familia, um programa de transferência de renda destinado às famílias em situação de pobreza (com condicionalidades nas áreas de saúde e educação), sendo considerado o carro-chefe do Fome Zero por executar a maior parte dos recursos orçamentários destinados à Segurança Alimentar; o PNAE, que oferece um complemento nutricional aos estudantes da rede pública de ensino; a distribuição emergencial de alimentos sobretudo a grupos populacionais específicos com maior grau de vulnerabilidade social; a construção de cisternas para a população rural do semi-árido; o apoio à instalação de Restaurantes Populares, que comercializam refeições prontas, saudáveis e a preços subsidiados em parceria com os municípios; a instalação de Bancos de Alimentos, que recebem doações de alimentos e os repassam gratuitamente a instituições beneficentes; o estímulo à implantação da agricultura urbana e de hortas comunitárias; a implantação do Sistema de Vigilância Alimentar e Nutricional (SISVAN), que é um conjunto de ações voltadas para o monitoramento do estado nutricional da população, que pretende descrever as tendências de saúde e nutrição e situações de insegurança nutricional; a distribuição de vitamina A (para puérperas e crianças de 6 meses a 5 anos, de áreas endêmicas) e de ferro (para crianças de 6 a 18 meses, gestantes e puérperas); o PAT, que objetiva melhorar as condições nutricionais dos trabalhadores em situação 
formal de emprego; a desoneração da cesta básica de alimentos; ações voltadas para a valorização de hábitos culturais saudáveis e a educação alimentar e nutricional [29].

Para o fortalecimento da Agricultura Familiar, do segundo eixo articulador, atuam o Programa Fome Zero; o PRONAF; o Garantia-Safra (para a região semi-árida brasileira), que é um benefício no período de seca; o Seguro da Agricultura Familiar, que cobre 100\% do financiamento e mais $65 \%$ da receita líquida esperada pelo empreendimento financiado pelo(a) agricultor(a) familiar; o Programa de Aquisição de Alimentos da Agricultura Familiar (PAA), que visa incentivar a produção de alimentos, a compra, a formação de estoques e a distribuição de alimentos para pessoas em situação de insegurança alimentar [28].

Para o terceiro eixo, a geração de renda, foram propostos programas de qualificação social e profissional; economia solidária e inclusão produtiva; o Consórcio de Segurança Alimentar e Desenvolvimento Local (CONSAD), que busca promover o desenvolvimento territorial em áreas periféricas do país, com ênfase na SAN e na geração de trabalho e renda; a organização produtiva de comunidades pobres, urbanas e rurais, de trabalhadores de empresas em processo de desestruturação produtiva e de catadores para triagem e beneficiamento do lixo; e a oferta de microcrédito a pessoas físicas e jurídicas empreendedoras de atividades produtivas de pequeno porte ${ }^{[28]}$.

Finalmente, no âmbito da articulação, mobilização e controle social, que formam o quarto eixo, o Fome Zero inclui as ações da proteção social básica da Assistência Social, desenvolvidas nos Centros de Referência em Assistência Social (CRAS); o programa de mobilização social e educação cidadã, que atua na capacitação, logística, elaboração e reprodução de material didático-informativo; o programa de capacitação de agentes públicos e sociais, por meio de oficinas, cursos e eventos; as ações solidárias de mutirões e doações; o incentivo às parcerias com empresas e entidades, principalmente para o desenvolvimento de projetos ditos estruturantes, dentre os quais se incluem ações voltadas para a geração de trabalho e renda; e o controle social, por meio de conselhos sociais, que participam e acompanham as ações do Fome Zero [28].

Idealizado como estratégia para assegurar o DHAA às pessoas com dificuldades de acesso aos alimentos, o Fome Zero recolocou o tema da fome nas agendas pública e governamental e se desdobrou em várias ações, como a imediata reativação do CONSEA e a aprovação da Lei Orgânica de Segurança Alimentar Nutricional, conhecida por LOSAN [2]. Também foram incentivadas as criações de conselhos estaduais e municipais de SAN.

Após o primeiro impacto, a marca "Fome Zero", aos poucos, foi saindo de cena para dar espaço ao conceito mais substantivo de SAN. Atualmente, a PNSAN é composta por um conjunto de ações denominadas estruturantes (ruptura com a dependência), específicas (direcionadas a segmentos populacionais ou regiões específicas) e locais (voltadas para o território urbano ou rural), assegurada por aporte jurídico e institucional [29].

\section{DISCUSSÃO}

Há cerca de 80 anos Josué de Castro apontava para a grave situação da má alimentação no Brasil. De lá para cá muita coisa avançou, tanto com relação ao diagnóstico que permitiu avaliar ao longo do tempo a extensão e gravidade dos níveis de desnutrição e de sobrepeso/obesidade, quanto com relação à forma de intervenção pública como um contraponto a esse problema.

Não se pode ignorar que as razões para esta situação são históricas, sendo resultado de um processo de formação econômica e social, já bastante abordado pela academia.

De meados do século XX até os dias de hoje, muitos programas governamentais foram lançados, tendo por motivação a insegurança alimentar e nutricional. Entretanto, esta longa experiência na implementação de diversos programas sociais voltados para esta questão tem sido caracterizada pela descontinuidade e desarticulação entre eles [29]. Se as principais referências internacionais para o combate à fome foram fruto da articulação dos povos no pós Segunda Guerra, no Brasil decorreram de movimentos sociais - de combate à ditadura militar e posteriormente à visão econômica hegemônica no final do século XX que culminaram na formação de uma força política que ascendeu ao poder na última década, motivo pelo qual a dinâmica da formulação da Política de Segurança Alimentar e Nutricional se intensificou neste período. 
Observa-se, portanto, que a consolidação desta experiência como uma política pública coerente e sistemática só tem se configurado na última década, sobretudo após o lançamento do Programa Fome Zero, devido ao fôlego que os atores governamentais e da sociedade civil ganharam para que a fome e a insegurança alimentar fossem tratadas como um problema macro e transversal, distanciando-se da visão de que programas focados e sem interface uns com os outros poderiam ser aplicados de forma efetiva para solucionar este mal, que ainda permeia a sociedade brasileira. A PNSAN, na letra da lei [2], engloba diversos ministérios entre eles o Ministério de Desenvolvimento Social e Combate à Fome, o Ministério da Saúde, o Ministério da Agricultura e o da Educação, demandando um elevado poder de conciliação e diálogo e ainda pressupõe a articulação de ações emergenciais e ações transformadoras da realidade econômica e social, sob um aparato institucional aparentemente adequado para tratar esse complexo problema ${ }^{[3,29]}$.

Os desafios de articulação, inerentes à transversalidade da SAN, associados à característica intrínseca da Política relacionada à articulação entre a área econômica, de gestão e de orçamento, são permanentes, sendo, portanto, necessário o investimento constante para sua continuidade e melhoria. Neste sentido, é muito positivo que o arcabouço institucional desta Política tenha sido construído e implantado como uma política de Estado, não mais de governos, tendo a LOSAN, de 2006, um papel relevante neste sentido.

O novo desafio que se coloca é a necessidade de aprimorar a Política atual para combater os problemas decorrentes da nova face da insegurança alimentar, pois se a fome e a desnutrição vêm saindo de cena da conjuntura brasileira, a obesidade e o sobrepeso estão ganhando proporções alarmantes, com graves consequências ao sistema de saúde do país.

\section{REFERÊNCIAS}

[1] Brasil. Constituição da República Federativa do Brasil. Brasilia, DF: Senado Federal; 1988.

[2] Brasil. Lei no 11.346, de 15 de setembro de 2006. Cria o Sistema Nacional de Segurança Alimentar e Nutricional, SISAN, com vistas a assegurar o DHAA e dá outras providências [acesso em 28 dez 2010]. Disponível em:
http://www.planalto.gov.br/Ccivil/ Ato20042006/2006/Lei/L11346.htm

[3] Burlandy L. A construção da política de segurança alimentar e nutricional no Brasil: estratégias e desafios para a promoção da intersetorialidade no âmbito federal de governo. Ciênc Saúde Colet. 2009;14(3):851-60.

[4] Burlandy L, Magalhães R. Segurança, seguridade e direito: as diferentes faces da questão alimentar e nutricional. Rio de Janeiro: Observatório da Cidadania; 2004.

[5] Castro J. Geografia da fome. São Paulo: Editora Brasiliense; 1946.

[6] Haute-Comissariat pour le Droit de l'Homme. 1966. Pacte international relatif aux droits économiques, sociaux et culturels. Le Haut Commissariat des Nations Unies aux droits de l'homme. 16 de dezembro de 1966 [acesso em 20 maio 2008]. Disponível em: http://www2.ohchr.org/french/law/cescr.htm

[7] Brasil. Decreto Legislativo no 226, de 12 de dezembro de 1991. Aprova os textos do Pacto Internacional sobre Direitos Civis e Políticos e do Pacto Internacional sobre Direitos Econômicos, Sociais e Culturais. Diário Oficial da União, Brasília, 13 dez. 1991. Seção 1, p. 2.

[8] III Conferência Nacional de Segurança Alimentar e Nutricional - Relatório Final 2007 [acesso em 15 mar 2011]. Disponível em: http://www4.planalto.gov.br/consea/publicacoes/publiu cacoes-arquivos/relatorio-final-iii-conferencia-nacionalde-seguranca-alimentar-e-nutricional

[9] Valente FL. Direito Humano à Alimentação: desafios e conquistas. São Paulo: Cortez; 2002.

[10] United Nations [homepage]. History of the United Nations. New York: UN; c2005 [acesso em 15 jun 2008]. Disponível em: http://www.un.org/aboutun/unhistory

[11] Flandrin JL, Montanari M. História da Alimentação. São Paulo: Estação Liberdade; 1998.

[12] Instituto de Pesquisa Econômica Aplicada; Secreatria de Estado dos Direitos Humanos; Ministério das Relações Exteriores. A segurança alimentar e nutricional e o direito humano à alimentação adequada no Brasil. Brasilia: IPEA; 2002.

[13] Brasil. Comitê Nacional para a Cúpula Mundial de Alimentação. Brasília (DF): Ministério das Relações Exteriores; 1996 [acesso em 15 mar 2011]. Disponível em: http://www2.mre.gov.br/dts/relatoriobras-CMA96.doc 
[14] Food and Agriculture Organization. Declaração de Roma sobre Segurança Alimentar Mundial e Plano de Ação da Cúpula Mundial da Alimentação. Roma: Cúpula Mundial da Alimentação; 1996 [acesso em 26 fev 2011]. Disponível em:

http://www.fao.org/docrep/003/w3613p/w3613p00.HTM

[15] Silva JG, Belik W, Takagi M. Projeto Fome Zero. São Paulo: Instituto da Cidadania; 2001.

[16] Moreira C. Soberania alimentar e alimentação adequada. Brasilia (DF): Presidência da Repúlica Federativa do Brasil [acesso em 30 maio 2009]. Disponível em: http://www.fomezero.gov.br/noticias/conferencia-faorepresentantes-brasileiros-discutem-soberania-alimentar

[17] Conselho Nacional de Segurança Alimentar e Nutricional [acesso em 16 março 2011]. Disponível em: http://www4.planalto.gov.br/consea/plenarias/plenariasde-2008/reuniao-do-dia-30-de-abril-de-

2008/apresentacao-territorios-da-cidadania-mda

[18] Escoda MSQ. Investimento no capital humano: Uma análise da política de nutrição - RN; Projeto Rio Grande do Norte; CNPq/FUNPEC, ano II, no 2 e 3, 05/1983.

[19] Fundo Nacional de Desenvolvimento da Educação. Alimentação escolar: encontros nacionais [acesso em 04 fev 2009]. Disponível em: http://ftp.fnde.gov.br/web/alimentacao escolar/encontr os nacionais/pnae historico e perspectivas 112005.pdf. $\underline{2005}$

[20] Silva AC. De Vargas a Itamar: políticas e programas de alimentação e nutrição. Estud Av. 1995;23:87-107.

[21] Arruda BKG, Arruda IKG. Marcos referencias da trajetória das políticas de alimentação e nutrição no Brasil. Rev Bras Saude Mater Infant. 2007;7(3):319-26.

[22] Pessanha L. Segurança Alimentar como um Princípio Orientador de Políticas Públicas: implicações e conexões para o caso brasileiro [tese]. Rio de Janeiro: Universidade Federal Rural do Rio de Janeiro; 1998.
[23] Brasil. Ministério da Saúde. Portaria no 710, de 10 de junho de 1999. Diário Oficial da União, Brasília, 11 jun. 1999. Seção 1, p. 14.

[24] Silva FF, Côrrea VP, Neder HD. Estudo comparativo da distribuição de recursos do PRONAF Crédito e Infraestrutura nas regiões sul e nordeste do Brasil: uma abordagem estatística. In: Ortega AC, Almeida Filho N. (orgs) Desenvolvimento Territorial, Segurança Alimentar e Economia Solidária. Campinas (SP): Editora Alínea; 2007.

[25] Brasil. Ministério da Saúde. Secretaria de Atenção à Saúde. Departamento de Atenção Básica. Política nacional de alimentação e nutrição. 2a ed. rev. Brasília: Ministério da Saúde; 2003. 48 p. (Série B. Textos Básicos de Saúde).

[26] Food and Agriculture Organization. Report of the 30th Session of the Committee on World Food Security (CFS). FAO Corporate Documet Repository [acesso em 21 maio 2008]. Disponível em: http://www.fao.org/docrep/meeting/008/J3345e/j3345e $\underline{01 . h t m}$

[27] Food and Agriculture Organization. Diretrizes Voluntárias em apoio à realização progressiva do Direito Humano à Alimentação Adequada no contexto da Segurança Alimentar Nacional. Brasília (DF): ABRANDH; 2005.

[28] Brasil. Fome Zero. Programas e Ações [acesso em 17 abril 2008]. Disponível em: http://www.fomezero.gov.br/programas-e-acoes

[29] Custódio MB. Política Nacional de Segurança Alimentar e Nutricional no Brasil: Arranjo Institucional e Alocação de Recursos [tese]. São Paulo: Programa Interunidades em Nutrição Humana Aplicada, Universidade de São Paulo; 2009. 